\title{
Assessment of the Economic Impact and Prevalence of Ovine Fasciolosis in Menz Lalo Midir District, Northeast Ethiopia
}

\author{
M Chanie*1 and S Begashaw ${ }^{2}$ \\ 1. University of Gondar, Ethiopia \\ 2. Menz Agricultural office, Menz Lalo Midir District, Ethiopia \\ * Corresponding author email: kasuamare@gmail.com \\ Received: 23-10-2011, Accepted: 26-11-2011, Published Online: 21-01-2012 \\ doi: $10.5455 /$ vetworld.2012.261-264
}

\begin{abstract}
Survey of economic loss and the prevalence of Fasciolosis in ovine species were conducted in Menz Lalo Midir district, Amhara National Regional State, during the period of September 2010 to June 2011. The objectives of this study were assessing the financial loss, determining prevalence. The total of number of study animals were 810 sheep from eight Kebeles (Tamawenze, Seklaye, Tayate, Saga, Wegere, Kilerbo, Toll, and Angetla) of Menz Lalo Midir district selected on lottery system. Prevalence was determined by fecal sample examinations. Gross lesions were studied by postmortem examination where as economic losses were determined after interview and market assessment. From fecal examination, the overall prevalence of ovine fasciolosis was found $70.20 \%$. The prevalence in male animals was found $50.6 \%$ and in females it was $19.6 \%$. But there exists no statistical significance between sex groups as the P value is less than 0.05 . During the study period 1,692.00 Ethiopian birr was lost due to condemnation of liver from 189 animals accounting $74.6 \%$ with 12.00 birr price of a liver. Clinically, observed signs were emaciation, weakness, bottle jaw and rough wool. Gross pathological lesions found were cirrhosis, fibrosis, and circumscribed pus accumulation, blunt edges of liver, bile duct hyperplasia and adult fasciola parasites on section of the liver. In conclusion, the results of the current study suggested that ovine fasciolosis was found to be one of the major disease entities in sheep in Menz Lalo Midir district.
\end{abstract}

Key Words: Economic loss, Menz Lalo Midir, Ovine fasciolosis, Prevalence

To cite this article : Chanie M and Begashaw S (2012) Assessment of the Economic Impact and Prevalence of Ovine Fasciolosis in Menz Lalo Midir District, Northeast Ethiopia, Vet. World. 5(5):261-264, doi: 10.5455/vetworld. 2012.261-264

\section{Introduction}

Liver is an important organ for all animals to carryout different activities and function for animals and a source of protein and valuable commodity for poor communities. Post mortem inspections, screening and sorting livers is important to separate the normal liver from abnormal (Assefa, 2005). In Ethiopia, many studies have been under taken to identify the major disease condition encountered during ante mortem and postmortem examination. The study conduct by (Mezgebu, 2003) at Nazareth and Gondar abattoirs respectively revealed that liver where highly rejected organ by postmortem inspections mainly due to fasciolosis.

Fasciolosis is an economically important disease of domestic livestock mainly in sheep and cattle (Abebe, 1995). The disease is caused by trematodes of genus fasciola. Commonly refereed as liver flukes (Lemma et al. 1985; Jones et al. 1997; Bowman,
2003). The two species of most commonly implicated, as the etiological agent of fasciolosis are Fasciola hepatica and Fasciola gigantica .Fasciola hepatica has a worldwide distribution but predominant in temperate zones, while Fasciola gigantica is also found in most continents primarily in tropical (FAO, 2009; Staurt, 1997; ). The adult flukes are found in the bile ducts and the immature flukes in the liver parenchyma. Fasciola gigantica (giant liver flukes) are similar shape to Fasciola hepatica but larger with less clearly defined shoulders. It causes economic loss in sheep and cattle of Africa mainly through liver condemnation.

Ovine fasciolosis in Ethiopia is very frequent and causes a significant economic loss either in production loss or decrease productivity and loss of body condition (Rahmeto et al., 2010; Abunna et al., 2010; Jibat, 2006; Daniel, 1995). However, this important disease was usually overlooked addressed and assessed all over the country. 
The study was therefore aimed to assess the economic losses due to Ovine fasciolosis, determine the current prevalence rate and associated risk factors in Menz Lalo Midir district.

\section{Materials and Methods}

Ethical approval: The study was approved by Institutional Animal Ethics Committee on 25th August, 2010.

Descriptions of the study area: The study was conducted from September 2010 to June 2011 in Amhara National Region State, North Shoa Zone, Menz Lalo Midir District. Menz is located at $276 \mathrm{~km}$ northeast of Addis Ababa. It is found at $10^{\circ} 09^{\prime}$ latitude north, $39^{\circ} 33^{\prime}$ longitudes east with elevations of 2,562 m.a.s.l. The mean annual rain fall in the area is 600 $\mathrm{mm}$. The monthly mean maximum temperature range from $15{ }^{\circ} \mathrm{c}$ to $24^{\circ} \mathrm{c}$. Likewise the monthly minimum temperature varies from $10^{\circ} \mathrm{c}$ to $14^{\circ} \mathrm{c}$ (Agricultural Development Offices of Menz Lalo Midir District, 2011; CSA, 2008). Most of the study kebeles were water lodged, swampy and marshy.

Study Population: Local breeds of 621 Menz sheep managed under extensive farming system in Menz Lalo Midir district of eight selected kebeles (peasant associations) and 189 sheep slaughtered in Mehal Meda local abattoir were the study animals.

Study design and sampling methods: A crosssectional study design was used to address the objectives of the study. The sample size required for the study was determined by using the formula given by Thrusfield (2005) by a simple random sampling technique. Accordingly, a total of 810 sheep comprising 621 clinicophysically examined and 189 were examined after slaughter. Fecal samples were collected directly from the rectum of the animals using disposable plastic gloves and placed in plastic bags that were labeled.

Laboratory examination: Laboratory examination was conducted using standard laboratory examination procedures (Urquhart et al., 1996). Fresh fecal samples were collected directly from the rectum, then three grams of feces were crushed using pestle and mortar; $40 \mathrm{ml}$ of water was added and then we let to sediment. The supernatant was discarded and the sediment part was put on the slid and observed under a microscope of 10x magnification power and identified the egg of fasciola from other nematodes and trematodes egg using identifying keys (Soulsby, 1982).

Postmortem examination: During meat inspection, the previously identified animals and their livers were carefully supervised and examined. The fluke recovery and count was conducted following the approach of Hammond and Sewell (1974). The gall bladder was removed and washed to screen out mature flukes. The liver was cut into slices of about $1 \mathrm{~cm}$ thick and put in a metal trough of warm water to allow mature flukes lodged out which were in smaller bile ducts and then the heads of the flukes were counted. Identification of the species involved was carried out using the size parameters described by Soulsby (1982). During the postmortem inspection, the liver was thoroughly inspected by visualization, palpation and incision for the identification and exposing of pathological lesion and parasites. Using this procedure a total of 189 liver was inspected according to the guide line on meat inspection for developing countries prepared by FAO (2009).

Economic loss assessment: The economic loss associated with liver condemnation was assessed using short communication and interview with the local people of sheep owners and local slaughter houses.

Data Analysis: Daily data were recorded in a spread sheet and it was analyzed using simple descriptive data analysis (SPSS version 17.0).

\section{Results}

Fecal examination: From a total of 621 fresh fecal samples $436(70.20 \%)$ were positive for fasciola eggs. Of 436 positive animals 314 were male and 122 were female. Therefore, the prevalence with respect to sex has indicated that it was serious in male animals than females $(50.6 \%$ and $19.6 \%)$ respectively.

Table-1.Prevalence of ovine fasciolosis obtained from fecal examinations in Menz sheep.

\begin{tabular}{lllc}
\hline Results & Sex & Number & Prevalence (\%) \\
\hline Positive & Male & 314 & 50.6 \\
& Female & 122 & 19.65 \\
Negative & Male & 59 & - \\
\multirow{2}{*}{ Sample Size } & Female & 126 & - \\
& Male & 373 & - \\
Total & Female & 248 & - \\
\hline
\end{tabular}

Postmortem examination: A total of 189 sheep slaughtered in the local slaughter house were thoroughly examined. Of these, 141 (74.60\%) livers were condemned due to sever pathological lesions. Some of the pathological lesions observed include cirrhosis, pus formation and calcification with gritting sound on cut, swelling of the liver and loss of its 
normal sharp edges, cholangitis and swelling of associated lymph nodes. We have also observed adult parasites in the bile duct. Among the adult fasciola parasites identified it was mainly the fasciola hepatica that predominates the specimen.

Table -2 . Number of sheep slaughtered, positive livers for fasciola and prevalence recorded from September, 2010 to January, 2011 in Menz Lalo Midir district

\begin{tabular}{lllllll}
\hline Month & Sept. & Oct. & Nov. & Dec. & Jan. & Total \\
\hline No of sheep slaughtered & 36 & 53 & 34 & 54 & 12 & 189 \\
No of Positive liver & 29 & 34 & 27 & 47 & 4 & 141 \\
Prevalence & 80.6 & 64.2 & 79.4 & 87.0 & 33.3 & 74.6 \\
\hline
\end{tabular}

Economic loss assessment through interview and short communications: From the total of 120 people interviewed about the major cause of the liver condemnation in the study area; it was indicated that $110(91.67 \%)$ replied it was fasciolosis (locally called "embuk"). They added that when they slaughter sheep for holidays and other ceremonies they were able to detect parasites, swellings with pus found accumulated inside and swollen liver with hard consistency. Three interviews were made with the local slaughter house attendants, a veterinary clinician and a veterinarian; they all agreed that the most important factor for the loss of liver is fasciolosis. They emphasized that among the most important endoparasites of small ruminants in the area; they were trematodes mainly of fasciolosis.

From inspected 189 livers in the local slaughter houses, 141 livers were condemned due to various pathological finding specially fasciolosis. This has shown that from 141 condemned livers the loss in birr is about 1, 692.00 Eth. Birr because at the time of this study a normal liver was locally cost 12.00 Eth Birr. This finding implied that the loss even from the edible offal liver alone due to fasciolosis accounts a tremendous loss if we have gone through for farther study on the market. The indirect loss due fasciolosis is farther incurred due to reduced productivity, reduced growth and expenses for the treatment of infected animals.

\section{Discussion}

Fasciolosis is a prevailing ruminant health predicament and causes substantial economic losses to the livestock commerce in Ethiopia. The prevalence indicated by fecal examination in the present study (70.20\%) was higher than the 51\%, $49 \%$ and $49 \%$ recorded for Debre Zeit, Holeta and Dawa-Cheffa by Micheal (2003) Yilma (1985) and Molalegne et al. (2010) respectively. Similarly, the postmortem examination discovered a higher prevalence of ovine fasciolosis (74.60\%). Much lower prevalence rate of $13.2 \%$ was recorded in the middle Awash River Basin by Ahmed et al. (2007). This difference might be attributed to the favorable ecological factors for the snail intermediate host and there by the parasite. This was because most of the kebeles have been water lodged, swampy and marshy which provide suitable habitats year round for the snail intermediate hosts (Argaw, 1998).

With regard to sex of animas, male $50.6 \%$ $(314 / 621)$ animals have found infected more than female $19.65 \%(122 / 621)$ animals which is completely different from $49.4 \%$ recorded finding by Molalegne et al. (2010) for female animals.

The postmortem of examination of animals depicted that 141 livers were found infected and condemned. This accounts loss of around 1692 Ethiopian birr. Correspondingly, fasciola infection has produced loss 106,400 Ethiopian birr (8312.5 USD) per annum at Hawassa reported by Rahmeto et al. (2010), an average loss of 4000 USD per annum at Soddo reported by Abunna et al. (2010), average 57,960 Ethiopian Birr (4,674.2 USD) per annum at Adwa Bekele et al. (2010) and 270,211.88 Ethiopian Birr or equivalent to 27, 572.64 USD per annum at Mekelle reported by Berhe et al. (2009) in cattle.

Estimation of economic losse due to fasciolosis at a national or regional level is, however, limiteed by lack of accurate estimates of the diseases prevelence, complexity in disaggregating and quantifying the direct and indirect effects of the disease and lack of a common methodology for assessing the economic loss. The annual loss due to endoparasitism includind fasciolosis in Ethiopia was estimated at 700 million Birr (Ngategize et al., 1993; Yimam, 2003). Decreased productivity alone due to ovine fasciolosis was estimated at 200 million birr by the year 2010 .

\section{Acknowledgements}

Authors are pleased to thank the technical staffs of Menz Lalo Midir District Veterinary Laboratory for their unreserved help in facilitating the laboratory works during this research.

\section{Conflict of interest} interest.

Authors declare that they have no conflict of

\section{References}

1. Abebe, G. (1995). Current status of Veterinary Education and animal health research in Ethiopia. In: 
Veterinary Medicine impact on human health and nutrition in Africa, In: proceeding of an international conference. 1-24.

2. Abunna, F., Loma, A., Bekele, M. and Alemayeh, R. (2010). Bovine Fasciolosis Coprological Abattoir survey and its economic impact due to liver condemnation at Soddo municipal abattoirs, Southern Ethiopia. Tropical Animal Health and Production, 42: 289-292.

3. Ahmed, E. F., Markvichitr, K., Jumwasorn, S., Koonawoothtthin, S. and Achoothesa J.S. (2007). Prevalence of fasciola species infection of sheep in the middle awash river basin, Ethiopia. Southeast Asian Journal of Tropical Medicine and Public Health, 38:51-52.

4. Argaw, K. (1998). Epidemiology of Bovine fasciolosis in Galama Awerja (ARSI). In Ethiopian Veterinary Association Preceding of the twelfth conference, 11-12 June, Addis Ababa, Ethiopia, 35-42.

5. Assefa, M. (2005). Parasitic causes of carcass or organ condemnation at Assela municipality abattoir, DVM thesis, Faculty of veterinary Medicine, Addis Ababa University, Debre Zeit, Ethiopia.

6. Bekele, M., Haftom, T. and Yehenew, G. (2010). Bovine Fasciolosis: Prevalence and its economic loss due to liver condemnation at Adwa Municipal Abattoir, North Ethiopia, Ethiopian Journal of Applied Sciences and Technology , 1:39-47.

7. Berhe, G., Kassahun, B. and Gebrehiwot, T. (2009). Prevalence and economic significance of fasciolosis in cattle in Mekelle Area of Ethiopia. Tropical Animal Health and Production, 41:1503-1504.

8. Bowman, D. D. (2003). Georgis' Parasitology for veterinarians. $8^{\text {th }}$ ed. Saunders, USA. 124-240.

9. CSA, (2008). Federal Democratic Republic of Ethiopia, Central Satirical Authority (CSA). Agricultural sample survey 2008/2009 (2009 E.C Report on livestock and livestock characteristics (Privet peasant Holding). Addis Ababa, 120-131.

10. Daniel, F. (1995). Economic importance of organ condemnation due to fasciolosis and hydatidosis in cattle and sheep slaughtered at Dire Dawa abattoir. DVM Thesis, Faculty of Veterinary Medicine, Addis Ababa University, Debre Zeit, Ethiopia.

11. FAO, (2009). Food and Agricultural Organization of United Nations. Livestock sector brief, Ethiopia livestock information, and sector analysis and policy branch. FAO, Rome, Italy.15.-16

12. Hammond, J. A. and Sewell, M. H. (1974). Floatation on to Sellotape (demonstration), transaction of the royal society of tropical Medicine and hygiene, 66: 547.

13. Jibat, T. (2006). Causes of carcass and organs condemnation in small ruminants slaughtered at Debre Zeit HELMEX abattoir. DVM thesis, Faculty of veterinary Medicine, Addis Ababa University, Debre Zeit, Ethiopia.

14. Jones, T. C., Hunt, R. D. and Norval, W. K. (1997). Veterinary Pathology $6^{\text {th }}$ ed. Hong Kong: Lippincott Williams and Wilkins, 651-654.

15. Lemma, G. Gebreab, F. and Jedla, S. (1985). Study on fasciolosis in four selected sites in Ethiopia. Journal of Veterinary Parasitology, 29-37.

16. Menz Lalo Midir District Agri. Dev. Office (2011). Annual report on weather and climate of the Menz Lalo Midir District.

17. Mezgebu, Y. (2003). Major cause of organ condemnation in small ruminants Slaughtered at Gondar abattoir, north western Ethiopia, DVM thesis faculty of Veterinary Medicine, Addis Ababa University, Debre Zeit, Ethiopia.

18. Micheal, G. B. B. (2003). Treatment and control of liver fluke in sheep and cattle. Technical notes, November, 2003. West Main roads, Edinburgh, 34-45.

19. Molalegne, B., Nurgadis, I.and Nahil, A. (2010). Study on the prevalence of ovine fasciolosis in and around Dawa- Cheffa, Kemissie. Africa Journal of agricultural Research, 5:2981-2985.

20. Ngategize, P. K., Bekele, T. and Tilahun, G. (1993). Financial losses caused by ovine fasciolosis in the Ethiopian Highlands .Tropical Animal Health and Production, 25 (3):155-161.

21. Rahmeto, A., Fufa, A., Mulugata, B., Solomon, M., Bekele, M. and Alemayehu, R. (2010). Fasciolosis: Prevalence, financial losses due to liver condemnation and evaluation a simple sedimentation diagnostic technique in cattle slaughtered of Hawassa municipal abattoir, Southern Ethiopia. Ethiopian Veterinary Journal, 14(1): 39-51.

22. Soulsby, E. J. L. (1982). Helminthes, Arthropod and Protozoa of Domestic animals $7^{\text {th }}$ ed. Bailliere and Tindal, London, UK. pp. 809.

23. Staurt, M.T. (19970. Fluke infection in ruminants, lung worm infection. The Merck Veterinary Medicine Manual $8^{\text {th }}$ ed.pp.1998.

24. Thrusfield, M. (2005). Veterinary Epidemiology $3^{\text {rd }}$, UK, Blackwell Scientific Publishing, UK. pp. 228247.

25. Urquhart, G. M., Armour, J., Duncan, J. L., Dunn, A M. and Jennings, F.W. (1996). Veterinary Parasitology $2^{\text {nd }}$ ed. Oxford, Longman Scientific and technical Press, UK. pp. 100-109.

26. Yilma, J. (1985). Study on ovine fasciolosis and other Helminthes parasite at Holeta DVM Thesis, Faculty of Veterinary Medicine, Addis Ababa University, Debre Zeit, Ethiopia.

27. Yimam, M. (2003). Major causes of organ condemnation in ruminant slaughtered at Gondar abattoir. DVM thesis, Faculty of Veterinary Medicine, Addis Ababa University, Debre Zeit, Ethiopia. 